Sino-UK educational differences: The impacts of cultures and the current educational curricular on students in computer science

Prapa Rattadilok

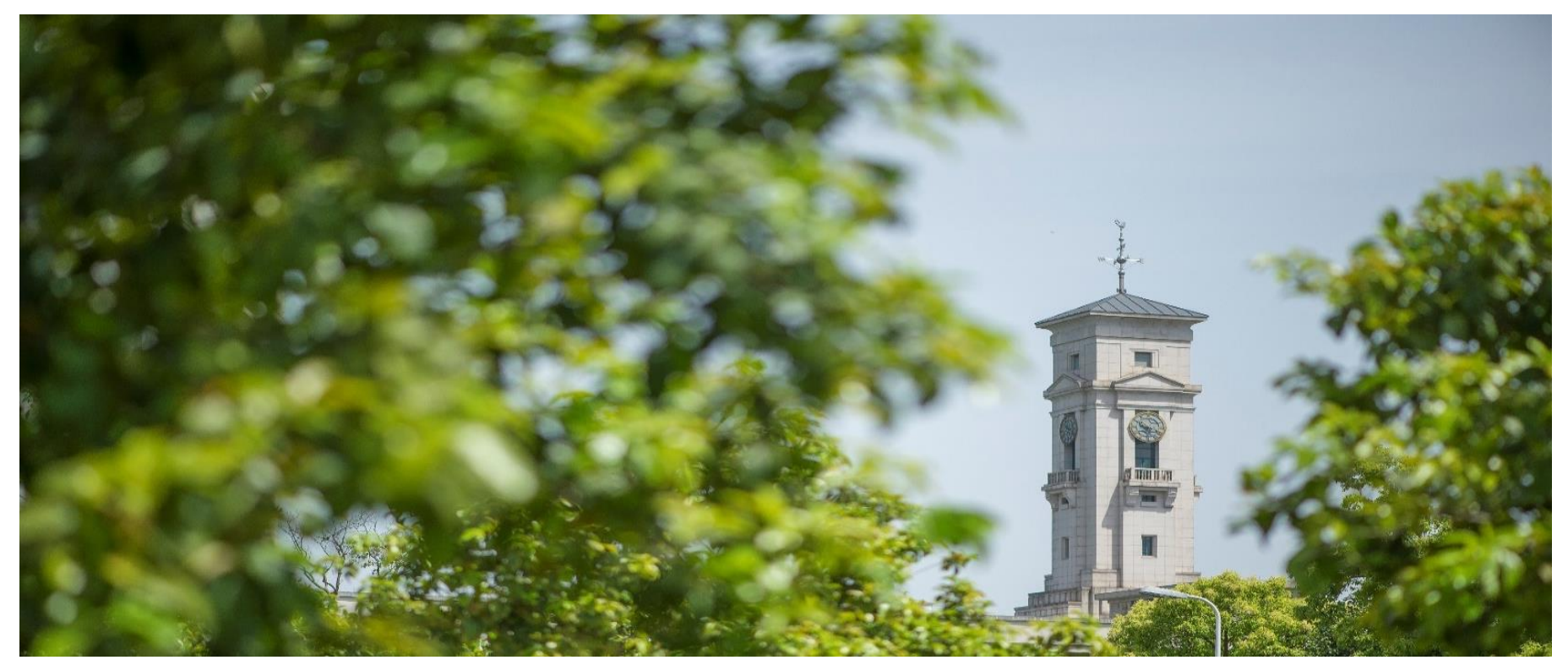


University of Nottingham Ningbo China, 199 Taikang East Road, Ningbo, 315100, Zhejiang, China.

First published 2019

This work is made available under the terms of the Creative Commons Attribution 4.0 International License:

http://creativecommons.org/licenses/by/4.0

The work is licenced to the University of Nottingham Ningbo China under the Global University Publication Licence:

https://www.nottingham.edu.cn/en/library/documents/research/global -university-publications-licence-2.0.pdf 


\section{Sino-UK Educational Differences: the Impacts of Cultures and the Current Educational Curricular on Students in Computer Science}

\section{Introduction}

Chinese students are a primary source of overseas students for most non-Chinese universities. Both the fierce competition within the Chinese universities and the recognition of the revenue from the international students by Western universities are contributing to the increased number of Chinese students in English-speaking countries. Whilst the cost of education in the UK is the highest of the English-speaking countries, the brand image and international rankings are most celebrated and respected in China (Edwards and Ran, 2006).

This chapter aims to highlight the differences in the compulsory educational structures in China and UK through the process of a thorough literature review, comparing the differences in the available subjects, perceptions of teaching and the assessment methods a student uses to decide on a university. This review focuses only on the mainstream curriculum and not the vocational courses for both the UK and China.

A questionnaire approach is used in order to gain further insight from senior secondary school students, undergraduate students, lecturers and parents. The latter half of the chapter focuses specifically on analysing the data from this questionnaire which focuses on Computer Science. The aim is to identify the relationship, if one exists, between culture and learning differences in order to highlight key areas for those delivering a British curriculum to focus on.

\section{Chinese Education}

Since the implementation of economic reforms and the open door policy in 1978, with a GDP growth rate between $7 \%-8 \%$ a year, China has become the world's second largest economy (World Bank, 2019). Over the last decade, China's investment in education has increased at a rate of $19 \%$ on average, and this investment is equal to $4 \%$ of GDP in 2012. Since 1956, all classes in schools, except for minority areas, were to use Mandarin Chinese i.e. Putonghua (Goldstick, n.d.b). The standardisation of the language also dramatically increased the literacy rate from $12 \%$ to the current literacy rate of between $86 \%$ and $90 \%$ (Goldstick, 2009). However, the sudden change from a traditional communist system to China's contemporary system, i.e. market-socialism, has led to inequality in access of education (Goldstick, n.d.a).

In addition to the central government, China's constitution consists of three levels of administration, which are provincial, county and township level. There are four kinds of provincial level divisions, which are province, municipality, autonomous region and special administered region.

\subsection{Compulsory Education}


China, the largest education system in the world, is educating 260 million young people and employs 15 million teachers in about 514,000 schools (OECD, 2016). Education is state-run where county-level governments have primary responsibility of the governing and delivering of primary and secondary school education. However, provincial authorities administer higher education institutions. In 2015, there were 2,852 county-level divisions in China (National Centre for Education Development Research and Chinese National Commission for UNESCO, 2008).

There are nine years of compulsory education in China. This consists of six years in primary school and three years in junior secondary school from the age of six to fifteen. The Law on Compulsory Education, revised in 2006, stipulates that all students are exempted from tuition fees in compulsory education and the parents are responsible for enrolling their children. The school year is divided into two semesters, i.e. fall and spring. Fall semester begins in early September and spring semester starts in late February (Ziklová, 2014). Classes begin by 8:00 am, splitting into four to five forty to fifty-minute periods in the morning, and three to four forty to fifty-minute periods in the afternoon. Many of these students will also attend some extracurricular activity after school before returning home and commencing their homework (china's education system 2014).

Memorisation and extensive test preparations are the main teaching methods in secondary school and university entrance examination or Gaokao (Mack, 2018). Nonetheless, according to research memorisation and Gaokao contribute to China's best knowledge in mathematics and science. According to the Programme for International Student Assessment (PISA) test in 2009, students in Shanghai, China received an average score of 600 in mathematics and 575 in Science, whereas the students in the United States received an average of 487 and 502 in mathematics and Science respectively (Goldstick, n.d.b).

\subsection{Optional Education}

Following the compulsory education, the government uses a public examination called Zhongkao to assign students that chose to continue with three years of senior secondary education, to different senior secondary schools. Although senior secondary schools are not compulsory, $94.9 \%$ of junior secondary students continued to senior secondary schools in 2017, an increase from 57.5\% in 1997 (National Bureau of Statistics of China, 2018). However, research shows that rural junior secondary schools receive an unequal quality of academic resources and unequal amount of education as well as preparation towards university entrance examination when compared to urban senior secondary schools (Goldstick, n.d.a). In fact, the last year of senior secondary school is targeted towards preparing the university entrance examination (Goldstick, n.d.b).

Undergraduate degrees require four years of study in China. Admissions to undergraduate programmes are based on the score of their entrance examination called Gaokao. The entrance examination itself is three-day duration and takes place in June or July each year. The exam takes nine hours, and is under high security where students are scanned to prevent them from using any electronic devices and the examination rooms is recorded by camera during the exams (Schrock, 2011). According to statistics, three out of five senior secondary students that attend the Gaokao pass the examination, where those that fail end up as blue-collar workers (Goldstick, n.d.b). The gross enrolment throughout China increased from 3.83 million in 2006 to 4.63 million in 2017 (UNESCO Institute of Statistics, 2019). This increment in the number of 
enrollees could be influenced by the reform, where some local governments allow longer termmigrant children to sit for examination in their hosting provinces instead of their domicile registration or Hukou province (National Bureau of Statistics of China, 2018).

In 2010, a national standardised student enrolment and status information management system was built. All students are assigned an enrolment number which is linked directly with their identification number. The whole education process of a student is recorded with this ID. This also impacts on their school enrolment according their residential information.

\subsection{Teachers and Teaching}

Like many Asian countries, teachers and teaching is highly respectable. In China, different qualification certificates are required for different types of teachers which can be applied for from local educational administration departments at the county level. The teacher's qualification examination is held nationally, separate examinations are provided for teacher certifications at pre-school, primary, secondary and vocational level of education. Every teacher's certificate applicant has to pass the examination including both written examination and interview. For higher education, the certification process is more complex, whereby some universities have the right to issue certificates, but all teachers at other universities must hold government-approved certificates (OECD, 2016).

\subsection{Curriculum}

The curriculum for junior secondary students mainly includes morality, Chinese, mathematics, foreign language, science (or physics, chemistry and biology), history and society (or history and geography), physical education and health, art and comprehensive practical activity. For senior secondary school, the government suggests that various elective subjects in addition to the compulsory subjects must be offered by schools. The comprehensive practical subject covers information technology, research study, community service, and social practice for primary and junior secondary school students. For senior secondary students, only research study, community service and social practice are covered.

The new curriculum reform was initiated in 2001 and focuses more toward essential knowledge and skills to lifelong learning; as well as active and problem-solving learning style.

\subsection{University Entrance}

From 2014, Shanghai and Zhejiang provinces have been the pilot regions of the new National University Entrance Examination or Gaokao. Instead of testing students on two broadly defined subjects i.e. art and science, the new test will be structured as a general examination which will consist of national unified exam and an assessment of academic proficiency. The national unified exam part include Chinese, mathematics and foreign language, whereas students can choose the disciplines according to their interests in the academic proficiency part i.e. relevant to their majors when applying for university admissions. In Zhejiang, a 3+3 model is used. For the national unified exam part, the foreign language is English. For academic proficiency, students can choose three subjects from physics, chemistry, biology, politics, history, geography 
and technology. Foreign language and two other selected subjects may be taken twice and the grades can be valid for up to two years. For the three subjects in the national unified exam, the maximum score is 150 each. For the subjects in academic proficiency, an alphabetical grade from $A, B, C$ and $D$ are given. Unlike in the past, students can now apply to any university regardless of their score or the tier the university is in.

\section{UK Education}

In England, Scotland, Wales and Northern Ireland, the respective local Departments of Education are responsible for education. The UK spend 90 billion pounds sterling or about $4.3 \%$ of the national income in England (Belfield et al., 2018). In 2017/2018, total spending on schools in England represented about 42 billion pounds sterling. There were only $4 \%$ of $16-17$ year-olds who are not in any form of education in 2017. The Teaching Excellence Framework are a set of metrics the government uses to incentivise universities to improve their performance and therefore this is one of the metrics students use to decide the quality of the education provided (Universities and Colleagues Admissions Service, 2019).

In the UK, student loans are also available for students in higher education. Rather than fixed repayments like mortgages, it should be noted that what students pay back depends on their income after graduating with the repayment threshold set at 25,000 and a write-off period of 30 years from graduation (Belfield et al., 2018).

\subsection{Compulsory Education}

Education in the UK is compulsory between the ages of 5 and 16 (18 in England). State schools are free to attend and over $90 \%$ of all school children attend this type of schools. For private schools, e.g. public schools, parents pay the fees. By law parents have the right to educate their children at home, if they can show they can do it. Their day begins at 9:00 am and finishes at 3:30 pm where one afternoon a week is usually dedicated to Physical Education. The academic year generally runs from September to July each year.

The main state examinations are the General Certificate of Secondary Education (GCSE) or O-level (Ordinary) and are usually taken at the age of 16. Usually students take 5 to 10 GCSEs and they must pass relevant GCSEs in order to do their A-level (Advanced). The exam results are in letter grades between $A^{*}$ to $G$, where $A^{*}, A, B$ and $C$ are the higher satisfactory grades; and $D$ to $G$ are the lower satisfactory grades. These letter grades are to be replaced by numeric values of between 9 and 1, this will be phased in during 2018 and 2019 (Nuffic, 2018).

English, English literature and mathematics account for around a third of GCSE achievements in England (Ofquals, 2013). Schools decide which tier they enter a student, for example, foundation tier will give access to grades $C-G$ whereas higher tier will give access to grades $A^{*}$-E. However, the plan is to un-tier this wherever possible to allow students to be awarded the highest possible grades reflecting to their performance during the assessment. In order to design suitable assessment(s) and assess students of all ability fairly, certain subjects 
are tiered. For example, mathematics GCSE is tiered and therefore provides sufficient challenges for able students, but should also not demotivate less able students. The recent change to enhance student's capability for workplace and A-level also includes focusing on realworld contexts and multi-step problems in mathematics and the use of grammar, spelling, and vocabulary in English and English literature (Breslin and Moores, 2015).

In the UK, $60 \%$ of students entering employment stop their education at the end of their GCSEs (Rushton and Wilson, 2015). Many employers take GCSE grades into account when deciding to give an individual employment or training opportunity. Similar to employment, GCSEs also determine fields of study in A-level and university. For example, if medicine, science or mathematics are of interest, then the right kind of GCSEs in certain sciences and mathematics are required (Breslin and Moores, 2015). Whilst employers are dissatisfied with how well school-leavers are at applying Mathematics they leant at school in the work place, there is also a large dropout rate during the transition from GCSE mathematics to A-level mathematics. For entry to most A-level mathematics courses, a grade B or higher are usually required, similar grades are also deemed as sufficient by the employers (Rushton and Wilson, 2015).

\subsection{Optional Education}

To continue to higher education in the UK, students have to attend two more years and take their A-level exams in three subjects at the age of 18. The exam take place in May or June and there are five grades which are A, B, C, D and E. Prospective students are required to submit their application a year prior to their intended admission date to the Universities and Colleges Admissions Service (UCAS). The general minimum requirement for admission via UCAS is 2 GCE A-levels and 3 GCSEs in 5 different subjects. Universities also specify their own requirements, but most degree programmes usually require the minimum of 3 GCS A levels and 3 GCSEs.

In the UK, undergraduate programmes are mostly 3 years with exception for Medicine, Veterinary, Dentistry and Architecture that have a duration of five to six years. Bachelor degrees are traditionally awarded in two separate domains: science and arts. An honour degree marks bachelor's degree programmes that have a higher study load and more exams than ordinary programmes within the same duration, and only those students completing honours programmes are able to continue their studies at post graduate level.

\subsection{Teachers and Teaching}

In England and Wales, Qualified Teacher Status (QTS) is required by all teachers in schools. In Scotland, a teacher needs a university degree which includes the Teaching Qualification of the General Teaching Council of Scotland. In Northern Ireland, a teacher needs a university degree or certificate which includes the teacher competences from Department of Education (British Council, 2005). There are a number of routes a teacher can take to obtain their QTS status e.g. university-led training, school direct courses, and Teach First's learning development programme (Waitzman, 2016). For higher education, institutions set their own requirements 
which can include the Postgraduate Certificate in Higher Education (PGCHE) or accreditation with the Higher Education Academy.

All trainee teachers must obtain their official certification of their suitability to work with children, which must be countersigned by the institution the teacher is working in (British Council, 2005), this may contribute to how the public view teachers as social workers (Hargreaves et al., 2007).

\subsection{Curriculum}

The national curriculum for secondary schools includes: English, mathematics, Science, History, Geography, Art, Music, Technology, Religious Education, Physical Education and a foreign language i.e. usually French or German. In England, Information and Communication Technology (ICT) is also a required subject (Qualifications and Curriculum Authority, 2005). The students themselves select their examination subjects as well as the number of subjects they want to take exams in their GCSEs which are available in over 45 subjects (Qualifications and Curriculum Authority, 2005).

\subsection{University Entrance}

Universities may ask for a specific number of GCSEs with specific minimum grades. For example, a number of medical courses may ask for five or more grades at the top of the range. Depending on the degrees, the universities may often require a minimum of a pass in English and mathematics. A number of universities ask that grades and number of subjects are achieved at one setting, in order to ensure that you can manage workload of this size in your study. For example, three A-levels taken in Year 13. Common facilitating subjects required by many degrees include mathematics, English literature, physics, biology, chemistry, geography, history and languages (Russell Group, 2018).

\section{Cultural Influences}

\subsection{Confucianism}

Confucianism is a Chinese religious and philosophical tradition dating back 2500 years, brought back by Kong Qiu (commonly known as Kong Zi) to restore social and political harmony of the ruling class and the literate elite. Confucius's thee major virtues are humanity 仁 (ren), ritual propriety 礼 (li) and filial respect 孝 (xiao). Humanity is regarded as to be humane. The ritual propriety is the outward expression that is consistent with cultural norms. Filial refers to the respect for elders. Confucianism focuses around the transformation of a person by learning from the past sages and teachers in order to realise their full potential (Adler, 2011). 
Confucianism's decline following the decline of Han dynasty, when popularity changed to Buddhism and Daoism. The major revival of Confucianism was strongly influenced by Buddhism with Zhu Xi as the dominant figure, who extend education in China to the PhD level. However, when Zhu Xi's system became the basis of the civil examination system, people who hoped to get government jobs began to memorise the interpretations of the Confucian tradition rather than understand the moral purpose of the system. Later on, Confucianism was used politically to support conservative agendas, particularly on the obedience of the elders and the strict subjugation of women to men (Adler, 2011).

The Zhu Xi's system may have influenced how the Chinese culture of learning to largely emphasise rote learning from an authority figure (either a teacher or a book) and reflecting upon that text internally. Voluntary interaction with teachers in an open class would be considered rude and interaction only occurs when students are invited to respond to the teacher on an individual basis, creating a typically teacher centred learning environment (Jin and Cortazzi, 2016). Jin and Cortazzi (2008) find that Chinese students say that they are capable of adapting to the expectations of Western universities, however in doing so they felt that their cultural heritage was being lost. Therefore the outward and collaborative interaction that is desired within a British institution is directly at odds with the Chinese culture of learning.

\subsection{British Empire's Influences}

At the height of the British Empire, it covered around $25 \%$ of the world's land surface and other areas were closely linked to it by trade. The expansion of the British Empire was driven by the quest for resources, i.e. to eat, to process and sell on, or valuables (Pagden, 2001), for the development of Britain's evolving economy. There are a lot of disagreement about when the British Empire began, some saying it was as early as the $12^{\text {th }}$ century, but the empire came to the end after the Second World War (The National Archives, n.d.).

The British Empire contributed to the nature of education through the functions of an elite schooling system. "Public schools" created a community of "gentlemen" i.e. identifiable elites that shared outlooks, values and codes of honour (McCulloch, 2009). According to Griggs (1994), intellectualism was not the reason why pupils achieved high prestige positions, but family background and therefore social class of their parents. Principles, character and manners were taught, ritualised and hidden within the curriculum. Prefects and hierarchies are amongst many other rituals which kept influencing the way of life of the colonised to live the lifestyle of the colonisers (Mayo, 2014).

Hegemony is leadership or dominance by one country or social group over the others (Antonio Francesco Gramsci 1891-1937). When it exists, the ideas of the dominance are viewed as natural, normal or even beneficial (Freestone, 2015). Language is one of the key examples to demonstrate the dominance of the West, in order to protect and promote their interests (Burns and Coffin, 2001). Hence, advanced English skills are perceived to be highly desirable, as it is used by the global elite. However, due to globalisation students see English as a form of social capital and not Western dominance (Freestone, 2015).

Whilst in ancient China, one develops into a person by learning their duty in relation to others, interdependently with human community, Western philosophical tradition conceive the same concept more individualistically. Aristotle distinguished a person from animal based on the 
capability to reason. When one is rational, they are therefore being able to make the right choice for their own sake. For Kant, a person's ability to be self-legislating, through their rational and autonomous behaviour, is most important to living a good life. For Utilitarianism, a person is defined by their will to right the course of action to experience happiness. These principles all point to how being a person also meant freedom, independence, and respect of the autonomy of all agents (Bockover, 2010).

\section{Survey Results}

\subsection{Choosing between Degrees and Universities}

A total 150 questionnaires have seen sent out to senior secondary school students, 125 of these were returned and usable. Out of the 125 students, $6.4 \%$ and $8 \%$ of them think that their parents are the only ones who make the decisions regarding which degree and which university they will be attending respectively. $14.4 \%$ and $22.4 \%$ of these students think that they themselves and their parents are making the decisions regarding which degree and which university they will be attending together, respectively. Out of the 125 students, $10.4 \%$ of these students also suggest that their teachers are either making these decisions with either themselves, or with themselves and the parents. One student in particular suggest that "the society" makes the decision regarding which university they are going to. It may be assumed that the student is referring to the Gaokao.

A total of 70 questionnaires have been sent out to undergraduate students, 46 of these were returned and usable. Out of the 46 students, only $4.35 \%$ of them think their parents are the only one who make the decisions regarding which university they will be attending. None of them think their parents are the only one who make the decisions regarding which degree they will be attending. When compared to the senior secondary school students, a higher number of these university students think they themselves and their parents are making the decisions together regarding which degree (21.74\%) and which university they will be attending $(34.78 \%)$. It is possible that, the students thought they were going to make the decisions by themselves when they were in senior secondary school, but the actuality changes when they are making these decisions. It is also interesting to note that, unlike the senior secondary students, none of the university students suggest any other individuals that will make these decisions with either themselves, or with themselves and the parents. However, $4.35 \%$ and $6.52 \%$ of these university students suggest that their Gaokao decides which degree and which university they are attending respectively.

A total of 70 questionnaires have been sent out to parents, 27 of these were returned and usable. Out of the 27 parents, $29.63 \%$ of them think that they themselves are the only one who make the decisions regarding both the degree and the university their child will be attending. If the parents are categorised by their countries of origin, 16 of the parents who participated are from China and $50 \%$ of them think that they themselves are the only ones who make the decisions regarding both the degree and the university their child will be attending. There are 
$22.22 \%$ of the 27 parents think they themselves and their children are making the decisions regarding which degree and which university they will be attending together. Figure AAA compares the importance of different factors when senior secondary school students, undergraduate students and parents use to decide which university they themselves or their children will be attending.

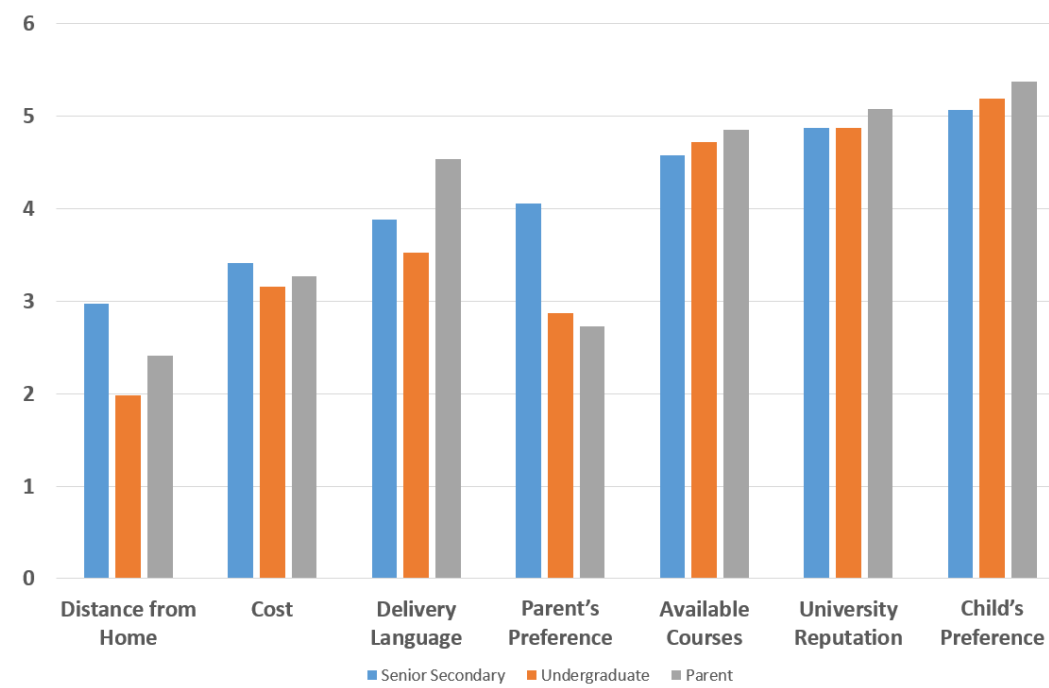

Figure AAA: The Importance of Different Deciding Factors.

Both students and parents are asked to rate the importance of different deciding factor with 1 being the least important or 6 being the most important. Distance from home is considered the least important from both the student's perspective as well as the parent's perspective. It is curious however that the child's preference are considered the most important from both perspectives, but $50 \%$ of the Chinese parents are making the decisions alone, regarding the degree as well as the university their children are attending.

It is also interesting to note a significant change, i.e. a decrease from 4.06 to 2.87 , between how the senior secondary students and the undergraduate students rate the importance of their parent's preference as the deciding factor. The average age of the senior secondary students and the undergraduate students who have completed the survey are 17.33 and 20.625 respectively. This represents a spread of 1-2 years before and after students begin their first degree i.e. generally at the age of 19. It may be possible that the undergraduates, having had the parent's advice for their first degree, they are now more confident in making their own decisions regarding the degree and the university they will be attending.

Delivery language is another interesting factor. For parents whose first language is Chinese, the importance of the delivery language is at 3.93. This number is much closer to the student's perspectives i.e. 3.88 and 3.52 for the senior secondary school students and the undergraduate students respectively. However, for parents whose first language is English, the importance of the delivery language is at 5.36. The survey also asked for "other deciding factors". Majority of the students input "food", "entertainment", "hardware" and "gym". One student in particular 
suggests that "politic and economic" are also part of their deciding factor. For parents, their answers suggest "employment record" and "safe city".

\subsection{Choosing between Home or Abroad}

Out of the 125 senior secondary students, $24 \%$ will not choose universities outside of their home country. The most common reasons are the familiarity with "the culture", "the country" and "the language". One student in particular noted the paramount importance was their safety in China over anywhere else in the world. Out of the 125 senior secondary students, $25.6 \%$ will only choose universities abroad. The two most common reasons for studying abroad for these students are to "see the world" and "attend better universities".

Out of the 46 undergraduate students, only three of them would not choose universities outside of their home country. However, their reason for not choosing universities outside of their home countries were their Gaokao results. Out of the 46 undergraduate students, $17.39 \%$ will only choose to attend universities abroad. Similar to the results from the senior secondary students, the two most common reasons for studying abroad for these students are "expand my horizon" and "quality of education". Although the senior secondary students have not provided any reasons why they would not choose to attend universities abroad, the undergraduate students suggest "financial situation" is one of the common reasons.

Out of 27 parents, $62.96 \%$ of them would allow their children to attend universities abroad. There is a difference between the parents whose first language is Chinese allowing their children to attend universities abroad i.e. $50 \%$ and the parents whose first language is English allowing their children to attend universities in China i.e. $36.36 \%$. However, for the parents whose first language is English, $81.82 \%$ of them would allow their children to attend universities abroad. Figure BBB compares the proportion of selected options between universities in their home country, universities abroad, or both.

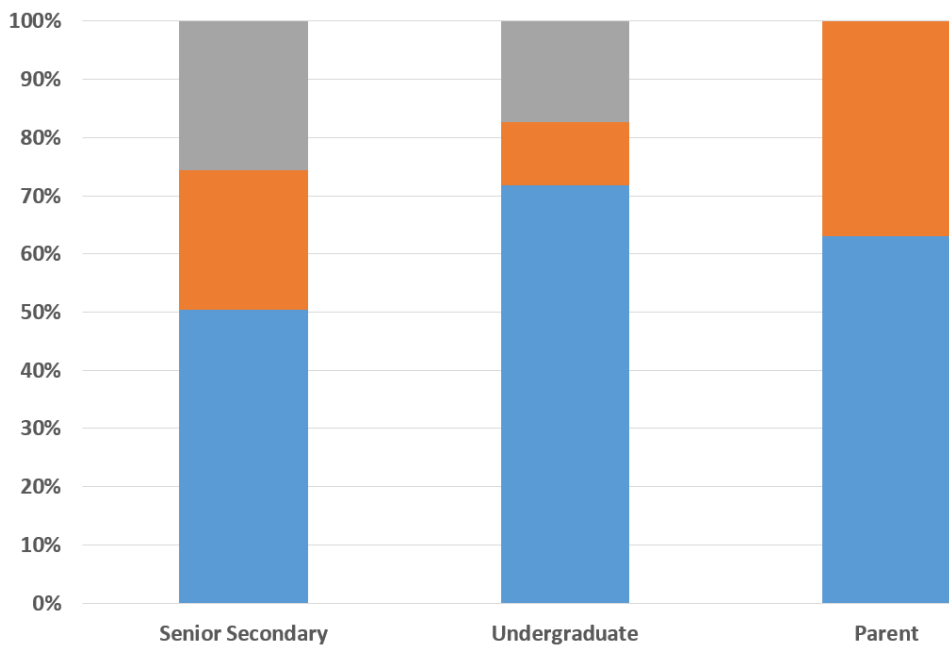

Figure BBB: Comparisons between Parent's and Student's choice when selecting a University in their Home Country or Abroad. 
From Figure BBB, it is "home only" in the least popular option amongst the students. It is also interesting to note that, from the parent's perspective, none of them would only allow their children to attend universities abroad but not home.

\subsection{Investments in Mathematics and Computer Science}

It is clear from the survey that both the students and parents think that Mathematics and Computer Science are important i.e. $96.49 \%$ and $94.15 \%$ from the student's perspective respectively and $100 \%$ for both subject areas from the parent's perspective. In addition to this, $94.15 \%$ of the students also think that Mathematics is important for Computer Science whereas it is $96.30 \%$ from parent's perspective. When asked for the main reasons why Mathematics is important for Computer Science, the most common answer from the senior secondary school student's perspective is "because Mathematics is the basic of Computer Science". It is interesting to note that undergraduate students are more precise with their answers and the most common answer is "because Mathematics is the basic of computer algorithms".

For senior secondary students, the two most common types of investments for both Mathematics and Computer Science are in the form of tutors and extra lessons. For undergraduate students, the two most common types of investments for both Mathematics and Computer Science are in the form of books and online courses. Figure CCC displays the survey results when students and parents are asked if they invest in Mathematics and Computer Science.

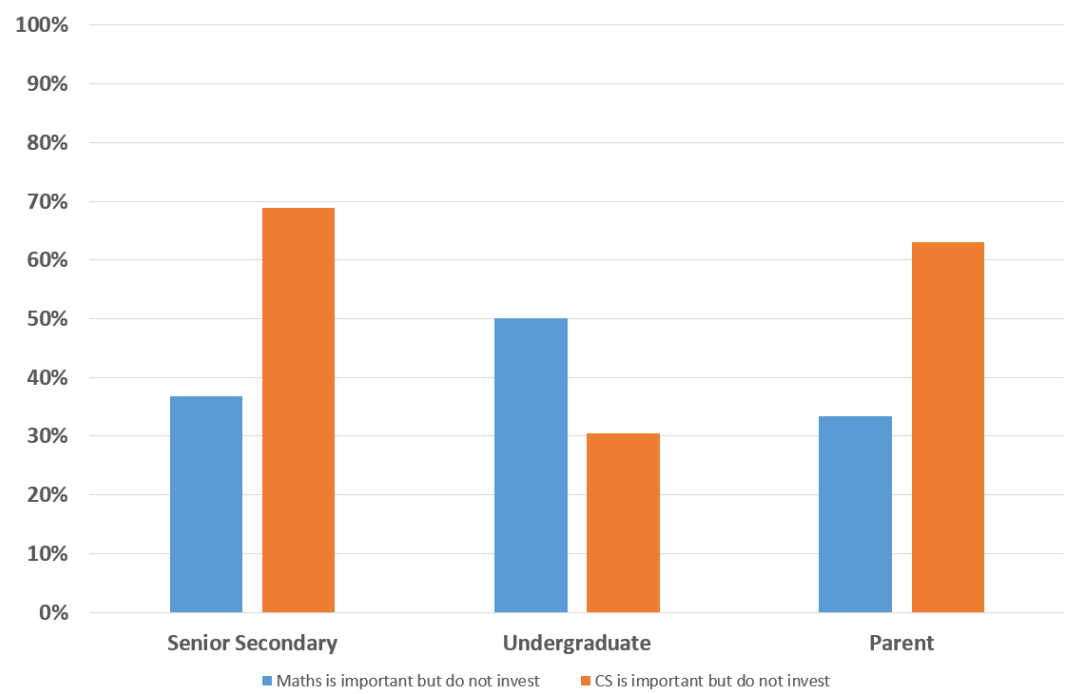

Figure CCC: Investments on Mathematics and Computer Science.

There are only $36.8 \%$ of the senior secondary students who think mathematics is important but they do not invest any extras outside of their curriculum, while there are $68.8 \%$ of the senior secondary students who think computer science is important but they do not invest any extras 
outside of their curriculum. It is interesting to note that whilst there are a massive differences between investment in Mathematics and Computer Science at the senior secondary school level, the difference is smaller in relative terms at the undergraduate level and also the opposite way around. In fact, there is more investment in Computer Science at the undergraduate level than Mathematics when compared to the senior secondary school level.

A similar reflection of the investments in Mathematics and Computer Science from the senior secondary student's perspective can be seen from the perspective of the parents. This possibly reflects the fact that the majority of the senior secondary school students are still living at home. One important point to note is the fact that, only $6.25 \%$ of the parents whose origin is Chinese recognise the importance of Mathematics but do not invest in any extra support outside of their children's curriculum, but $72.73 \%$ of the parents whose origin is not Chinese recognise the importance of Mathematics but do not invest in any extra support outside of their children's curriculum. For Computer Science, only $50 \%$ of the parents whose origin is Chinese recognise the importance of subject area but do not invest in any extras outside of their children's curriculum, but $81.82 \%$ of the parents whose origin is not Chinese recognise the importance of Computer Science but do not invest in any extras outside of their children's curriculum. Other than Mathematics and Computer Science, "Language" and "Chemistry" are the two most popular investments for the parents whose origin is Chinese, whereas "music" and "sport" are the most popular investments for the parents whose origin is not Chinese.

\subsection{Quality of the Degree}

When asked about the quality of the degree from different countries in Asia and Europe, where 1 being the worst and 6 being the best, it is clear that both the students and the parents agree that UK's degree are among the best with the average rating of 4.93 from the students and 5.32 from the parents. From the student's perspective, degrees from China is only marginally better than degrees from other European countries i.e. 4.57 and 4.56 respectively. However, the difference widens and is in a reverse polarity from the parent's perspective i.e. 4.19 and 4.82 respectively. Figure DDD: displays the box and whisker plot of the rating of the degree quality.

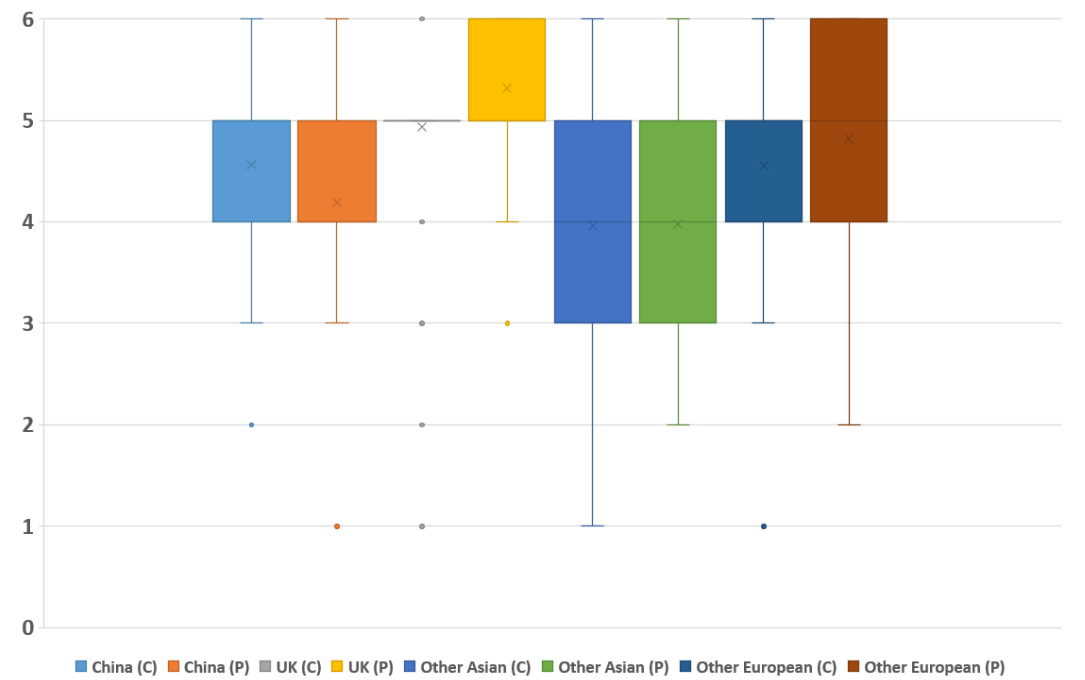


Figure DDD: Comparisons of the Rating on the Degree Quality from Different Regions.

Figure DDD shows the minimum, the first quartile, mean, the third quartile, the maximum and the outlier values. The $x$ in the box represents the mean. The bottom (top) line of the box represents the median of the bottom (top) half or the first (third) quartile. The whiskers extend from the ends of the box to the minimum value and the maximum value. The interquartile range is defined as the distance between the first quartile and the third quartile. Data points that exceed a distance of 1.5 times the interquartile range below (above) the first (third) quartile are considered outliers.

\subsection{Level of Mathematics and Computer Science Skills}

When the students were asked to compare their skills in Mathematics (Figure EEEa) and Computer Science (Figure EEEb) with students from different countries in Asia and Europe, where 1 being the worst and 6 being the best, it is clear that the students view themselves as having lower skills than other students from other countries in Europe and Asia. When excluding students from China, the difference is only marginal in the case of Mathematics skills i.e. 3.84 and 3.99, but the gap widen in the case of Computer Science i.e. 3.47 and 4.35 .

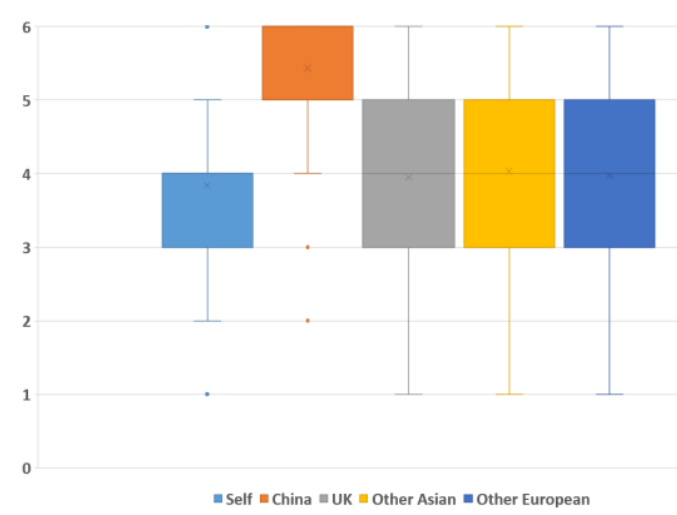

(a)

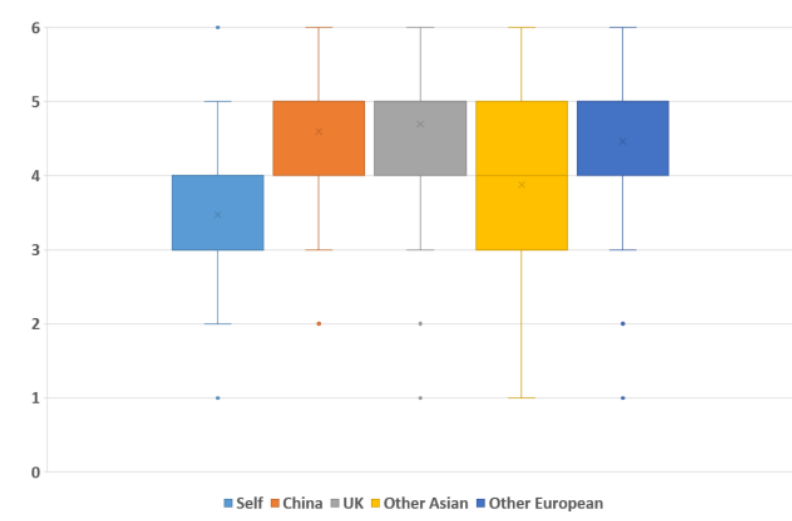

(b)

Figure EEE: The Student's Perspective of the Rating on Skills in (a) Mathematics and (b) Computer Science.

Although humbleness may affect how the students view their level of skills, it is clear that the students view the Chinese students as having a much higher level of skills in Mathematics than other countries in Asia and Europe. At the same time, the students view the UK students as having a slightly higher level of skills in Computer Science, but only marginally better when compare to their view on the Chinese students i.e. 4.70 and 4.60 respectively.

A total of 70 questionnaires have been sent out to university lecturers, 31 of these were returned and usable. The average number of years in teaching experience of these teachers are 2.53 in China, 7.32 in the UK, 4.57 in other Asian countries, and 1.27 in other European 
countries. Figure FFFa and FFFb display the number of counts on different ratings in Mathematics and Computer Science respectively from the teacher's perspective.

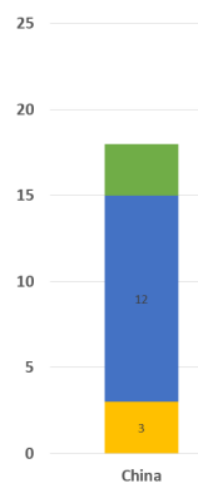

China

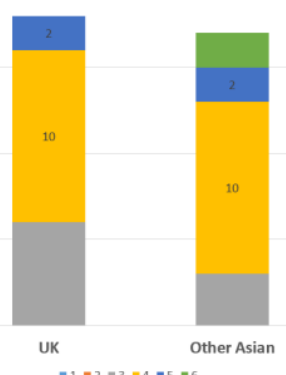

(a)

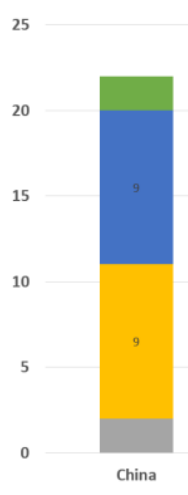

Other European

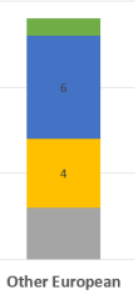

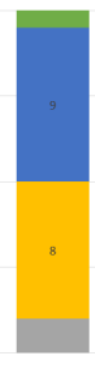

UK

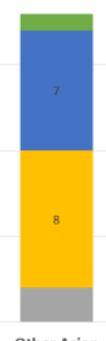
$=6$

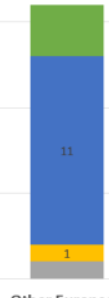

Other European

(b)

Figure FFF: The Teacher's Perspective of the Rating on Skills in (a) Mathematics and (b) Computer Science.

When comparing Figure EEE with Figure FFF, it can be seen that both the student and the teachers share similar views on the difference between the skills rating of Chinese students and UK students, where gap is much wider in (a) Mathematics than in (b) Computer Science. For Mathematics, the majority of the teachers rate Chinese students as 5 and rates UK students as 4 with the averages of 5 and 3.78 respectively. For Computer Science, the majority of the teachers rate Chinese students as 6 and 5 equally and rates UK students as 5 . However, the average is much closer when compared to Mathematics i.e. 4.5 and 4.45 between Chinese and UK students respectively.

\subsection{English as a Delivery Language}

Figure GGG displays the teacher's opinions in terms of receiving (i.e. listening and reading) and transmitting (i.e. speaking and writing) skills in English of students from Asian countries and European countries. 


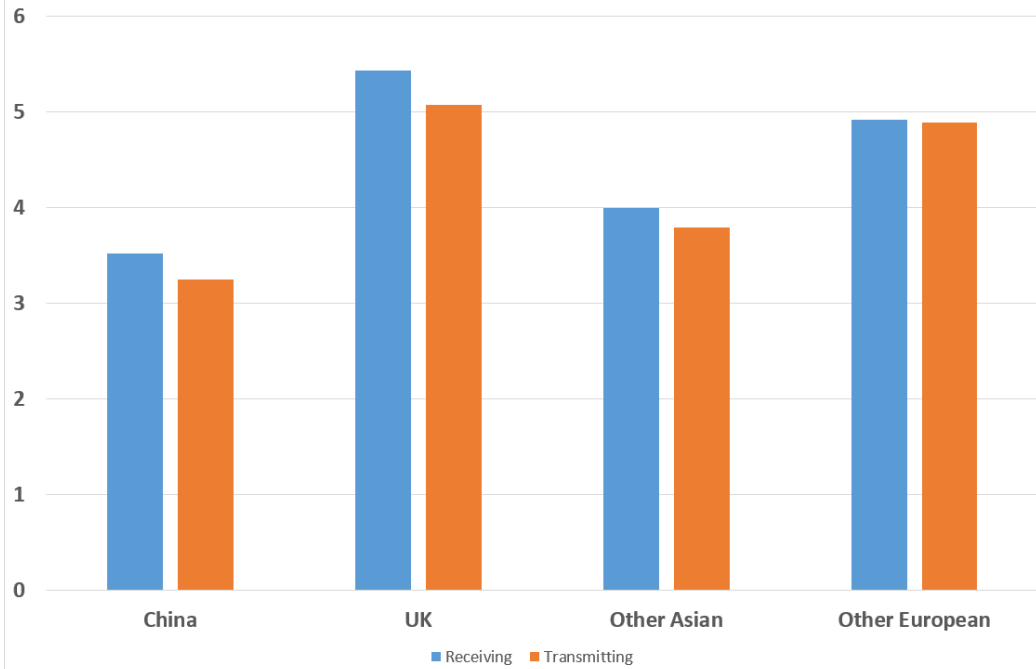

Figure GGG: The Average Ratings for Receiving and Transmitting Skills in English of Students from Different Countries.

Unsurprisingly, the UK students are rated at the top in both receiving and transmitting skills, closely follows by those in Europe. Chinese students are rated slightly lower amongst other in the same region. Out of the 31 lecturers, only $32.26 \%$ and $38.71 \%$ thinks delivery language will present a problem when teaching Mathematics and Computer Science respectively. One lecturer in particular suggests that language is used for the exchange of ideas and in fact "Native English speakers are a minority of speakers of scientific English now".

When asked if the culture plays a role in learning Mathematics and Computer Science, $61.29 \%$ and $64.52 \%$ of teachers agree in both of the subject areas, although this is not to say that the lecturers who think culture play a role in learning Mathematics will also think culture plays a role in Computer Science. A number of lecturers used the terms "memory" or "memorise" to describe the relationship between Mathematics and culture. One lecturer in particular suggests that "Some cultures are very accepting of authority. Cultures used to questioning and demanding evidence are more conducive the mindset needed to do mathematics". From the Computer Science viewpoint, one lecturer suggests that "We have a lot of students studying CS here [China] who don't want to do CS but are doing it to appease parents' wants. This doesn't happen in UK". Another lecturer suggests that "if access has previously been restricted etc. so resulting in a more limited experience and background knowledge". It is possible that in this case "access" refers to the Internet which is known to be very restrictive when compare to the rest of the world.

\section{Limitations}


The questionnaires for the students and parents were distributed within the east coast of China and East Midlands (UK). Specifically for students in China, the questionnaire was distributed only to those that are able to understand English.

The questionnaires for the teachers were distributed within Ningbo (China), and UK wide. However, this is limited to the lecturers in three subject areas including Mathematics, Computer Science, Engineering and English for Academic Purpose (Computer Science).

\section{Conclusions}

Despite cultural contradictions, Gu (2011) observes that all students, regardless of cultural background, mature and gain independence during their higher education experience; therefore, this is likely to lead to more autonomy, confidence and familiarity with educational expectations. Parents play a role in student's learning through their investment. Culture indirectly plays a role in the choice of investments the parent's made as well as how the students learn and therefore excel in certain subject areas. In Computer Science, delivering UK content to Chinese students will require certain terminologies and jargon to be clearly introduced and explained, possibly less so in Mathematics. Particularly when, unlike the UK, Computer Science or even Information Technology are not a part of the compulsory education in China.

The teachers need to take notice of the student's mentality with regard to adapting the content. For example, formative assessments which are popular in the UK may be more suitable for students who actually want to learn the subject areas, but less so if the students were there only to please their parents. Although the ideal goal of the institution may be to teach them the British Style of education, a gentle introduction may be required allowing them time to adapt to the new culture e.g. classroom interactions as a part of the summative assessments in the beginning of their British Style of education which gradually reduces its significance to formative assessments.

The need to develop British and Chinese awareness of differences exists and should be addressed to ensure that all students can fulfil their potential. Edwards and Ran (2006) highlighted a number of issues including teacher-student relationships, learning styles, plagiarism and group work. Being culturally intelligent also allows for effective communication in cross-cultural environments, which is of significance in any international operation including higher education sector (Esther and Olukayode, 2018).

\section{Reference}

World Bank (2019) Gross domestic product 2017. World Development Indicators Database. Available via http://databank.worldbank.org/data/download/gdp.pdf. Accessed 22 April 2019.

National Centre for Education Development Research and Chinese National Commission for UNESCO (2008) National Report on Mid-Term Assessment of Education for All in China. Available via https://unesdoc.unesco.org/ark:/48223/pf0000207018. Accessed 22 April 2019. 
National Bureau of Statistics of China (2018) Net Enrolment Ratio of School-age Children in Primary Schools and Promotion Rate of Graduates of Regular School by Levels, China Statistical Yearbook 2018. http://www.stats.gov.cn/tjsj/ndsj/2018/indexeh.htm. Accessed 22 April 2019.

OECD (2016) Education in China: A Snapshot. Available via https://www.oecd.org/china/Education-in-China-a-snapshot.pdf. Accessed 22 April 2019.

UNESCO Institute of Statistics (2019) Enrolment by type of Institution, Education Database. www.uis.unesco.org/Education/Pages/default.aspx. Accessed 22 April 2019.

Ziklová A (2014) Primary and Secondary Education in USA and China: Comparison of Approach and Purpose. Thesis, Masaryk University.

Mack L (2018) Introduction to School and Education Systems in China. Available via https://www.thoughtco.com/school-and-education-in-china-688243. Accessed 22 April 2019.

Schrock J R (2011) Education Frontlines. Available via http://educationfrontlines.net/newspaper/0177.html. Accessed 22 April 2019.

Goldstick W (n.d.a.) China's Modern Educational System and its Disparities Can we close this gap?. University of Massachusetts, Amherst. Available via https://www.academia.edu/3692095/Chinas_Modern_Educational_System_and_its_Disparities_ Can_we_close_this_gap. Accessed 22 April 2019.

Goldstick W (n.d.b) The Gaokao Examination: A Shadow behind China's Educational System, Contemporary Chinese Studies I. Available via

https://www.academia.edu/3692103/The_Gaokao_Examination_A_shadow_behind_Chinas_ed ucational_system. Accessed 22 April 2019.

Goldstick W (2009) "One State, One People, One Language" The Language Reform Movement in China. Available via

https://www.academia.edu/3692117/_One_State_One_People_One_Language_The_Language _Reform_Movement_in_China. Accessed 22 April 2019.

Nuffic (2018) Education System United Kingdom, Described and Compared with the Dutch System. Available via https://www.nuffic.nl/documents/301/education-system-unitedkingdom.pdf. Accessed 22 April 2019.

Ofquals (2013) Reforms to GCSEs in England from 2015, Summary. Available via https://assets.publishing.service.gov.uk/government/uploads/system/uploads/attachment_data/fi le/529385/2013-11-01-reforms-to-gcses-in-england-from-2015-summary.pdf. Accessed 22 April 2019.

Qualifications and Curriculum Authority (2005) GCSEs, the Official Student Guide to the System. Available via

http://www.rewardinglearning.org.uk/microsites/applied_ict/docs/GCSE_Guide05.pdf. Accessed 22 April 2019.

Rushton N, Wilson F (2015) Teachers' and Enployers' views on the Transition from GCSE Mathematics to A level Mathematics or Employment. Available via

https://www.cambridgeassessment.org.uk/Images/302674-teachers-and-employers-views-on- 
the-transition-from-gcse-mathematics-to-a-level-mathematics-or-employment.pdf. Accessed 22 April 2019.

Breslin T, Moores M (2015) Starting GCSEs, You guide to Exam Success. A Cambridge University Press Transition Guide. Available via http://www.breslinpublicpolicy.com/wpcontent/uploads/Starting-GCSEs-your-guide-to-exam-success-PUBLISHED.pdf. Accessed 22 April 2019.

British Council (2005) Teacher Training. Available via https://www.britishcouncil.fr/sites/default/files/learning-infosheets-teacher-training.pdf. Accessed 22 April 2019.

Waitzman E 2016 Teachers at Academies and Free Schools: Qualifications. House of Lords, In Focus. Available via https://dera.ioe.ac.uk/28844/1/LIF-2016-0044.pdf. Accessed 22 April.

Hargreaves L, Cunningham M, Hansen A, Mclntyre D, Oliver, C (2007) The Status of Teachers and the Teaching Profession in England: Views from Inside and Outside the Profession.

Available via

https://webarchive.nationalarchives.gov.uk/20130323010453/https://www.education.gov.uk/publi cations/eOrderingDownload/RR831A.pdf. Accessed 22 April 2019.

Russell Group (2018) A Russell Group Guide to Making Decisions about post-16 Education. Informed Choices. Available via https://www.russellgroup.ac.uk/media/5686/informed-choices2018-1-6th-edition-final.pdf. Accessed 22 April 2019.

Belfield C, Farquharson C, Sibieta L (2018) 2018 Annual Report on Education Spending in England. Institute for Fiscal Studies. Available via https://www.ifs.org.uk/uploads/publications/comms/R150.pdf. Accessed 22 April 2019.

Universities and Colleagues Admissions Service (2019) Teaching Excellence Framework (TEF) - What you need to know. https://www.ucas.com/undergraduate/what-and-wherestudy/choosing-course/teaching-excellence-framework-tef-what-you-need-know. Accessed 22 April 2019.

The National Archives (n.d.) British Empire Overview. Available via http://www.nationalarchives.gov.uk/education/empire/intro/overview2.htm. Accessed 22 April 2019.

Pagden A (2001) Peoples and Empires: A Short History of European Migration, Exploration, and Conquest from Greece to the Present. Modern Library, New York.

McCulloch G (2009) Empires and Education: The British Empire. In: Cowen R, Kazamias A M (eds) International Handbook of Comparative Education. Springer International Handbooks of Education, Vol 22. Springer, Dordrecht.

Griggs C (1994) Review: The Influence of British Public Schools on British Imperialism. British Journal of Sociology of Education 15(1): 129-136.

Mayo P (2014) Education, Imperialism and Critical Pedagogy. Available via https://www.counterpunch.org/2014/05/19/education-imperialism-and-critical-pedagogy/. Accessed 22 April 2019. 
Burns A, Coffin C J (2001) Analysing English in a Global Context. Routledge, London.

Freestone P (2015) English in Global University Education: Issues of Hegemony and Global Elite Dominance in Chinese Contexts. In: International Proceedings of Economics Development and Research. Available via http://www.ipedr.com/vol83/003-C013.pdf. Accessed 22 April 2019.

Bockover M I (2010) Confucianism and Ethics in the Western Philosophical Tradition I: Foundational Concepts. In: Philosophy Compass 5/4 (2010): 307-316. Available via https://onlinelibrary.wiley.com/doi/pdf/10.1111/j.1747-9991.2010.00295.x. Accessed 22 April 2019.

Edwards V, Ran A (2006) Meeting the needs of Chinese students in British Higher Education. Available via https://blogs.shu.ac.uk/internationalnetwork/files/2013/07/MeetingTheNeeds.pdf. Accessed 22 April 2019.

Esther O D, Olukayode O A (2018) Cultural Influences on Negotiations between the Chinese and the British in Higher Educational Settings in the UK. In: Trends in Technical and Scientific Research 2(5). Available via https://juniperpublishers.com/ttsr/pdf/TTSR.MS.ID.555598.pdf. Accessed 22 April 2019.

Adler J A (2011) Confucianism in China Today. Pearson Living Religions Forum. Available via https://www2.kenyon.edu/Depts/Religion/Fac/Adler/Writings/Confucianism\%20Today.pdf. Accessed 22 April 2019.

Jin L, Cortazzi M (2008) Changing Practices in Chinese Cultures of Learning. In: Language, Culture and Curriculum, 19 (1): 5-20.

Jin L, Cortazzi M (2016) Practising Cultures of Learning in Internationalizing Universities. In: Journal of Multilingual and Multicultural Development, 38 (3): 237-250.

Gu Q (2011) An Emotional Journey of Change: The Case of Chinese Students in UK Higher Education. In Jin L, Cortazzi M (eds), Researching Chinese Learners: Skills, Perceptions and Cultural Adaptations. Palgrave MacMillan, Basingstoke. 